\title{
NÚMERO CROMOSÓMICO DE DOS ESPECIES MEXICANAS DEL GÉNERO Diospyros, ZAPOTE PRIETO (EBENACEAE)
}

\section{CHROMOSOME NUMBER OF TWO MEXICAN SPECIES OF THE Diospyros GENUS, ZAPOTE PRIETO (EBENACEAE)}

\author{
Hugo A. Farías-Chagoya*, María L. Ballesteros-Almanza', José \\ L. Abrego Aranda' y Marco A. Arciga-Sosa'
}

'Facultad de Biología, Universidad Michoacana de San Nicolás de Hidalgo, Morelia, Michoacán, México.

*Autor de correspondencia (fariaschagoya@yahoo.com)

\section{RESUMEN}

\begin{abstract}
Se realizó un conteo cromosómico en dos especies mexicanas del género Diospyros, (zapote prieto) de la familia Ebenaceae, Diospyros xolocotzii Madrigal \& Rzed. y Diospyros digyna Jacq. El análisis citogenético se realizó en células somáticas de ápices radicales pretratados con una solución saturada de para-diclorobenceno, durante 5 horas a $4{ }^{\circ} \mathrm{C}$ y fijadas en Carnoy. La tinción de los cromosomas se obtuvo con Feulgen y carmín acético al 1 $\%$. Los resultados obtenidos nos muestran que el número cromosómico para ambas especies fue de $2 n=2 x=30$, lo que indica que los dos taxa son diploides, ya que los conteos reportados para la mayoría de los representantes de este género son de $2 n=2 x=30$, con un número básico de $x=15$.
\end{abstract}

Palabras clave: Diospyros xolocotzii, Diospyros digyna, diploide, número cromosómico.

\section{SUMMARY}

Chromosome counting was carried out in two mexican species of the Diospyros genus, (zapote prieto) of Ebenaceae family, Diospyros xolocotzii Madrigal \& Rzed. and Diospyros digyna Jacq. The cytogenetic analysis was performed in somatic cells of root tips pretreated with a saturated solution of para-dichlorobenzene, for $4 \mathrm{~h}$ at $4{ }^{\circ} \mathrm{C}$ and fixed in Carnoy. The chromosomes staining was obtained with Feulgen and $1 \%$ acetic carmine. The results obtained show that the chromosome number for both species was $2 n=2 x$ $=30$, which indicates that these two species are diploid, as the chromosome numbers reported for this genus in most species is $2 n=2 x=30$, with a basic number $x=15$.

Index words: Diospyros xolocotzii, Diospyros digyna, chromosome number, diploid.

\section{INTRODUCCIÓN}

La familia Ebenaceae está constituida por cuatro géneros y 548 especies, de las cuales la mayoría pertenecen al género Diospyros, reportándose para este género entre 480 y 500 especies (Wallnöfer, 2014). Las demás se encuentran repartidas en Euclea (16 a 20), Lissocarpa (5 a 10) y Tetraclis (3); todas reportadas en el continente africano (Hyde et al., 2012).
Diospyros es el único género mexicano representante de esta familia, con aproximadamente 20 especies conocidas en el país (Duarte y Paull, 2015). Éste, al igual que otros géneros mexicanos, enfrenta problemas relacionados con su taxonomía; además, especies como $D$. riojae y $D$. xolocotzii (Madrigal y Rzedowski, 1988), cuya importancia radica en la comercialización de su fruto y su madera (Singh y Joshi, 2011), se encuentran en la Norma Oficial Mexicana NOM-059 ECOL-2001 como vulnerables y en peligro de extinción (Denisse, 2010).

Los estudios citogenéticos, como el número cromosómico y las características del cariotipo, al igual que la morfología externa y los marcadores moleculares (Guan et al., 2019), pueden ser de gran utilidad en la taxonomía de las especies. Sin embargo, pocos estudios citogenéticos se han llevado a cabo en el género Diospyros, debido a sus pequeños cromosomas, cuyo intervalo de longitud en metafase es de 2 a $3 \mathrm{~mm}$, haciendo difícil la observación al microscopio óptico (Choi et al., 2002; Tamura et al., 1998) La mayoría de los estudios se han centrado en el número cromosómico de células somáticas de 42 especies a nivel mundial, principalmente originarias de Asia y África (Goldblatt y Johnson, 2006).

Los números cromosómicos reportados en especies silvestres de Diospyros son en su mayoría diploides $(2 n=$ $2 x=30$ ), con pequeños números de especies tetraploides $(2 n=4 x=60)$, mientras que, para especies de plantas cultivadas, así como D. kaki, son hexaploides $(2 n=6 x=$ 90). Algunos cultivares sin semilla de $D$. kaki han sido reportados como nonaploides $(2 n=9 x=135)$ (Tamura et al., 1998; Zhuang et al., 1990). También se han reportado para Diospyros lotus L. números diploides $(2 n=2 x=30)$ y para $D$. virginiana números de $2 n=4 x=60$ y $2 n=6 x=90$, lo que sugiere que también son tetraploides y hexaploides. Estos resultados indican que el número básico $(x)$ de 
cromosomas del género Diospyros es de 15 (Yonemori et al., 2000). En especies mexicanas del género Diospyros no existen estudios citogenéticos, por lo cual, el objetivo de esta investigación fue determinar el número cromosómico de Diospyros xolocotzii Madrigal y Rzed y Diospyros digyna Jacq, especies del género Diospyros nativas de México.

\section{MATERIALES Y MÉTODOS}

El material biológico de Diospyros xolocotzii fue colectado en la Mintzita, municipio de Morelia, Michoacán, México, sitio localizado en las coordenadas geográficas $19^{\circ} 38^{\prime} 43^{\prime \prime}$ latitud norte y $101^{\circ} 16^{\prime} 29^{\prime \prime}$ longitud oeste, a una altitud de 1923 metros sobre el nivel del mar (msnm). A su vez, Diospyros digyna fue colectada en el municipio de Venustiano Carranza, estado de Puebla, México, entre las coordenadas geográficas, $20^{\circ} 29^{\prime} 17^{\prime \prime}$ latitud norte y $97^{\circ}$ $33^{\prime} 21^{\prime \prime}$ longitud oeste, a una altitud de 75 msnm.

Se colectaron frutos de cinco individuos de ambas especies y las semillas se pusieron a germinar en un suelo enriquecido con agrolita y peat moss, en una proporción 1:1 $(v / v)$. La producción de la plántula se realizó en condiciones de invernadero. Se utilizaron cortes de ápices radiculares para el análisis citogenético, mismos que se probaron en diferentes pre tratamientos, siendo el más adecuado la solución saturada de para-diclorobenceno $2.5 \mathrm{ml}$ durante 5 horas a $4{ }^{\circ} \mathrm{C}$, para el acortamiento adecuado de los cromosomas; posteriormente, los cortes fueron colocados en el fijador Carnoy, formado por alcohol etílico absoluto, ácido acético glacial y cloroformo, en proporción 6:1:1 v/V. Las raíces fueron hidrolizadas en ácido clorhídrico $1 \mathrm{~N}$ por 15 minutos a $60{ }^{\circ} \mathrm{C}$ y teñidas con el reactivo de Feulgen por 2 horas. Las preparaciones se realizaron utilizando el método de aplastado (squash), reforzando la tinción con carmín acético al 1 \% (García, 1988).

Las observaciones cromosómicas se realizaron en al menos veinte células por genotipo, seleccionando aquellas que presentaran los cromosomas separados. Los recuentos cromosómicos se hicieron en un microscopio óptico marca Leica modelo DM E, con el objetivo 100X mediante la observación directa y las fotomicrografías tomadas mediante una cámara Samsung con circuito cerrado de televisión, mediante el programa TV@anyware plus de Micro-Star Int'l Co., Ltd.

\section{RESULTADOS Y DISCUSIÓN}

El análisis citogenético de las dos especies de Diospyros (Diospyros xolocotzii Madrigal \& Rzed. y Diospyros digyna Jacq.) nos permitió determinar que el número cromosómico en ambas especies es de $2 n=2 x=30$, lo que indica que son plantas diploides y que su número básico de cromosomas es de $x=15$ (Figuras 1A y 1B). Es importante mencionar que el número básico y nivel de ploidía para las especies aquí estudiadas es consistente con lo encontrado en la mayoría de las especies de este género (Goldblatt y Johnson, 2013), ya que se han encontrado números cromosómicos de $2 n=4 x=60$ en $D$. cathayensis, D. lycioides, $D$. ramulosa y $D$. rhambifolia, de $2 n=6 x=90$ en $D$. cathayensis, $D$. kaki y D. virginiana y de $2 n=9 x=135$ en $D$. kaki, números cromosómicos que indican que se tratan de especies tetraploides, hexapolides y nonaploides, respectivamente (Yonemori et al., 2000; Choi et al., 2002; Goldblatt y Johnson, 2013)

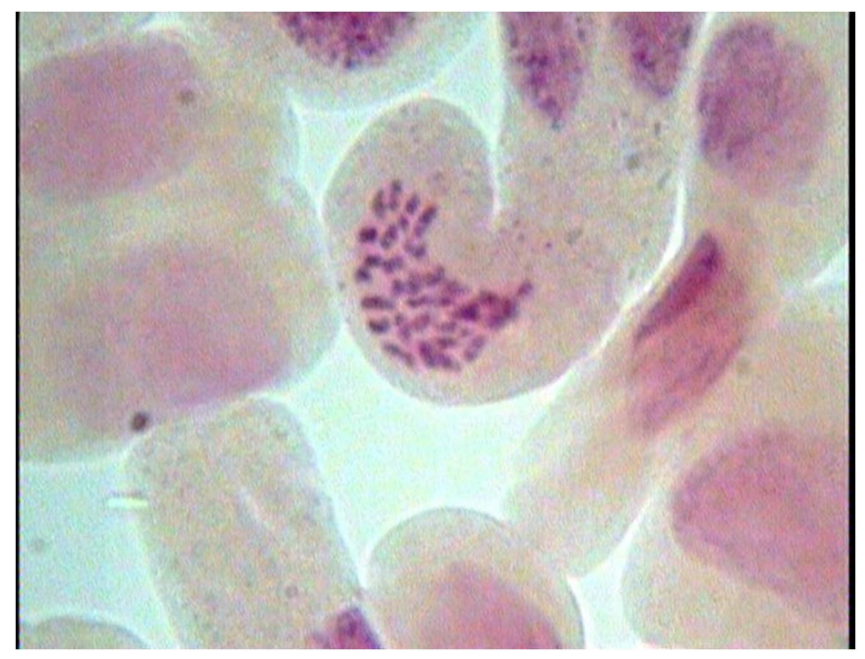

Figura 1A. Cromosomas de células mitóticas en meristemos radiculares de Diospyros xolocotzii. La barra equivale a $10 \mu \mathrm{m}$. 


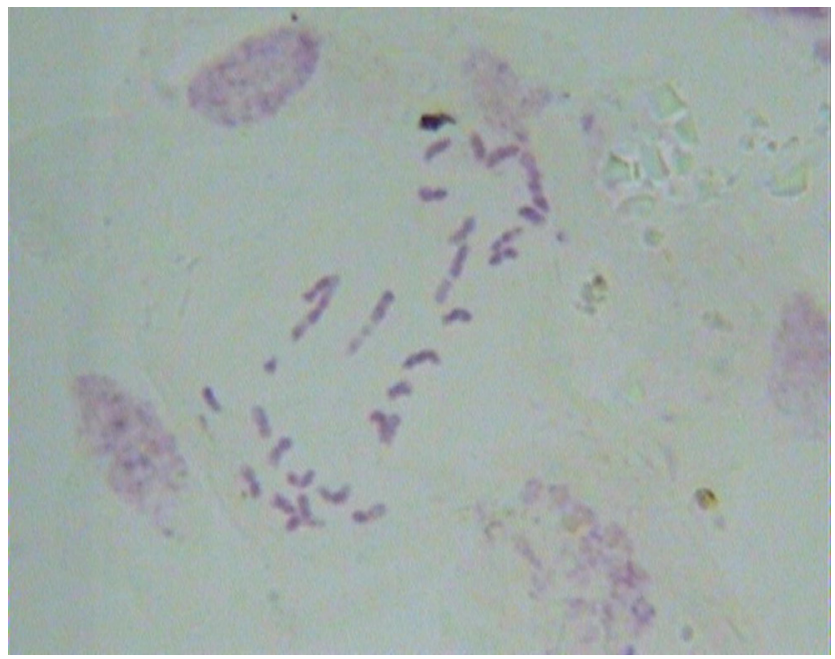

Figura 1B. Cromosomas de células mitóticas en meristemos radiculares de Diospyros digyna. La barra equivale a $10 \mu \mathrm{m}$.

El número cromosómico para Diospyros xolocotzii Madrigal \& Rzed. y Diospyros digyna Jacq. es de $2 n=2 x$ $=30$, lo que indica que son genotipos diploides con un número básico de $x=15$.

\section{BIBLIOGRAFÍA}

Choi Y. A., R. Tao, K. Yonemori and A. Sugiura (2002) Multicolor genomic in situ hibridization identifies parental chromosomes in somatic hybrids of Diospyros kaki and D. glandulosa. HortScience 37 : 184-186, https://doi.org/10.21273/HORTSCI.37.1.184

Denisse S. (2010) Norma Oficial Mexicana NOM-059-SEMARNAT-2010: Protección ambiental-especies nativas de México de flora y fauna silvestres-categorías de riesgo y especificaciones para su inclusión, exclusión o cambio-lista de especies en riesgo, https://www.dof.gob.mx/normasOficiales/4254/semarnat/ semarnat.htm (Noviembre 2021).

Duarte O. and R. E. Paull (2015) Exotic fruits and nuts of the new world. Tracy head editors. 317 p., https://doi.org/10.1079/ 9781780645056.0000

García V. A. (1988) Técnicas y Procedimientos de Citogenética. $3^{a}$ Edición. Universidad Autónoma Chapingo. Chapingo, México. $198 \mathrm{p}$.

Goldblatt P. and D. E. Johnson (2006) Index to Plant Chromosome Numbers. Monographs in Systematic Botany from the Missouri Botanical Garden. 242 p., https://doi.org/10.2307/25065898

Goldblatt P. \& D. E. Johnson (2013) Index to plant chromosome numbers.
1979 onwards, http://www.tropicos.org/Project/IPCN.

Guan C. L. S., W. Mengke, J. Hao, R. Xiaofeng, W. Renzi and Y. Yong (2019) Comparative transcriptomic analysis reveals genetic divergence and domestication genes in Diospyros. BMC Plant Biology 19: 227, https://doi.org/10.1186/s12870-019-1839-2

Hyde M. A., B. T. Wursten and P. Ballings (2012) Flora of Zimbabwe: species information. Última modificación del sitio 17 de octubre de 2011, http://www.zimbabweflora.co.zw/speciesdata/ literature-display.php?literature_id=261

Madrigal S. X. and J. Rzedowski (1988) Una especie nueva de Diospyros (Ebenaceae) del municipio de Morelia, estado de Michoacán (México). Acta Botánica Mexicana 1:3-6, https://doi. org/10.21829/abm1.1988.557

Singh S. and H. Joshi (2011) Diospyros kaki (Ebenaceae): a review. Asian J. Res. Pharm. Sci. 1:55-58, https://doi.org/10.5958/2231-5659

Tamura M. R., R. Tao, K. Yonemori, N. Utsonomiya and A. Sugiura (1998) Ploidy level and genome size of several Diospyros species. Journal of the Japanese Society for Horticultural Science 67: 306-312, https://doi.org/10.2503/jjshs.67.306

Wallnöfer B. (2014) A revision of neotropical Diospyros (Ebenaceae): part 7. Annalen des Naturhistorischen Museums in Wien. Serie B für Botanik und Zoologie. pp 153-179.

Yonemori K., A. Sugiura and M. Yamada (2000) Persimmon genetics and breeding. Plant breeding reviews 19: 191-225, https://doi. org/20063179622

Zhuang D. H., A. Kitajima, M. Ishida and Y. Sobajima (1990) Chromosome numbers of Diospyros kaki cultivars. Journal of the Japanese Society for Horticultural Science 59: 289-297, https://doi. org/10.2503/jjshs.59.289 
